plants has been investigated by C. D. Nelson and P. R. Gorham (Canadian J. Bot., 37, 3, 431 (1959)) with the following results. In all, the translocation of each of seven amino-acids and three amides was measured for periods of 5 minutes or less after introduction through the cut petiole of a primary leaf. The compounds used were asparagine, urea, glutamic acid, glutamine, glycine, norleucine, arginine, serine, alanine and aspartic acid. During the short times of these experiments it was found that each compound was translocated downwards as such. The amount of carbon-14 in the stem decreased logarithmically from the point of introduction. Each compound was translocated with unchanged velocity past a short section of stem killed with steam. There was no translocation of aspartic acid through a stem that had an entire internode killed with steam. Potassium eyanide $\left(10^{-2} M\right)$ did not inhibit the velocity of translocation of any of the compounds although the logarithmic pattern of distribution of arginine was altered. The minimum velocity of translocation was different for each compound and varied between $350 \mathrm{~cm}$. per $\mathrm{hr}$. for asparagine and $1400 \mathrm{~cm}$. per $\mathrm{hr}$. for aspartic acid. The authors have also reported on the physiological control of the distribution of these substances (Canadian J. Bot., 37, 3, 439 (1959)). From the point of introduction, translocation of each amino-acid or amide was mainly downward towards the root; very little was translocated upward Both excision of the roots and chilling decreased the velocity of downward translocation of aspartic acid, indicating that the roots exert a strong 'demand' which favours translocation in a downward direction more than an upward direction in the stem.

\section{Volcanic Activity on the Moon}

In a brief article, N. A. Kozyrev (Priroda, 3, 84; 1959) describes his observations of the Moon since 1955 and provides a critical examination of the records of the Alphonse crater on November 3, 1958. In his opinion the spectrographic evidence suggests strongly that an eruption of volcanic ash did take place on that date on the Moon. This eruption was followed by the emission of gases containing $C_{2}$ molecules.

\section{Astronomische Gesellschaft Star Catalogues}

BeTweEn 1868 and 1908 the Astronomische Gesell schaft organized the production of a catalogue of all the stars brighter than the ninth magnitude in the northern sky. A dozen observatories shared in this work, the observations being made visually using meridian circles. It was later decided to repeat the whole programme photographically, and new observations were obtained during the years 1928-32. The Hamburg Observatory photographed the sky north of $+20^{\circ}$ declination, the Bonn Observatory that from $+20^{\circ}$ to $-2^{\circ}$. Observations of 14,000 reference stars were made at several observatories. The measure. ment of the photographs and the reduction of the measures have been in progress since 1932, and publication of the results began in 1951. The results are contained in a fifteen-volume catalogue, and the last five volumes of this catalogue have recently been published. The catalogue contains the positions of 180,000 stars down to magnitude $11 \cdot 5$. No proper motions for the stars were deduced because it was impossible to free the earlier catalogues from systematic errors. The homogeneity of the results of this large undertaking represents one of its most important features, and the catalogue is, and will remain, a landmark in positional astronomy. The catalogue is known as the $A G K 2$.

It has been decided to repeat the whole catalogue with a mean epoch of about 1960. 18,000 secondary reference stars are being observed at various observatories; the photography is being performed at Hamburg and 1,939 plates will be required. It is hoped to have positions and proper motions for all the 180,000 stars by 1965 . This new catalogue, the $A G K 3$, will enable astronomers to determine the systematic errors of old catalogues, connect the proper motions of the bright stars with those of fainter stars measured relative to the extragalactic nebulæ, and provide much data for geodetic purposes.

\section{Courses in Chemical Engineering}

A NEw pamphlet, "Scheme for a Full-time Course in Chemical Engineering" (pp. 16. London : Institution of Chemical Engineers, 1959. 2s.), is a revised version of the "Scheme for a Degree Course in Chemical Engineering", originally issued in 1944, and takes account of current developments in teaching chemical engineering at technical colleges. The course covers three years, and although in the first two years most of the time is spent on physical, organic and inorganic chemistry, the physics of solids, electricity, and mathematics, fluid mechanics, heat and mass transfer, the design and construction of process plant, power thermodynamies and engineering drawing are introduced at this stage and not left until the final year. In this year the course comprises fluid and particle mechanics, heat and mass transfer, separation processes, applied chemical thermodynamics and kinetics, fuels and combustion and design problems. Practical exporience in works is regarded as an essential adjunct to the course, and the economic aspect should be introduced into lectures on chemical process principles in the first year. The course should not be so rigid as to preclude transfer to chemical engineering in the earlier years by students who have commenced studies in a cognate faculty.

\section{Talanta Medal}

THE board of editors of Talanta announces a new award to be known as the Talanta Medal. The publishers, Pergamon Press, are providing the funds for this Medal, which will have a value of 100 guineas and which will be awarded for outstanding contributions to analytical chemistry. The Medal will not normally be awarded more frequently than once a year, but no attempt will be made to award it at any stated intervals. This award will be either to analytical chemists who are responsible for major developments in the subject or to scientists whose work is judged to have contributed in a substantial way to the developments in the field of analytical chemistry. Applications should be sent to the editors of Talanta, c/o Pergamon Press, 4-5 Fitzroy Square, London, W.I.

\section{Perkin Centenary Trust}

THE programme of awards for the year 1960-61 will include one Perkin Centenary Fellowship, valued at not less than $£ 600$ a year, which is available to a graduate for advanced studies, and two Perkin Centenary Scholarships at $£ 300$ a year, which are intended to give young persons employed in the industries concerned with the manufacture or the application of colouring matters the opportunity of full-time education at a university or technical 